Original Article

\title{
The association between systemic inflammation and the time spent in posture and movement during daytime in patients with chronic obstructive pulmonary disease and lower weight
}

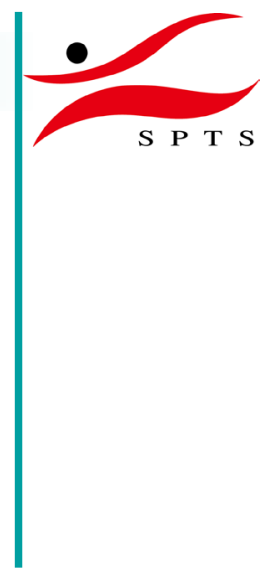

\author{
Atsuyoshi Kawagoshi, RPT, $\mathrm{PhD}^{1)^{*}}$, Masahiro Iwakura, RPT, $\mathrm{PhD}^{1)}$, \\ Yutaka Furukawa, RPT, MScli), KeiYu Sugawara, RPT, PhD ${ }^{1)}$, \\ Hitomi Takahashi, RPT, PhD 2 , , TAKanobu Shioya, MD, $\mathrm{PhD}^{3)}$ \\ 1) Department of Rehabilitation, Akita City Hospital: 4-30 Kawamoto Matsuoka-cho, Akita City, Akita \\ 010-0933 Japan \\ 2) Department of Physical Therapy, School of Health Sciences, International University of Health and \\ Welfare, Japan \\ 3) Department of Physical Therapy, Akita University Graduate School of Health Sciences, Japan
}

\begin{abstract}
Purpose] The effect of physical activity on systemic inflammation remains unclear and might be negative in patients with chronic obstructive pulmonary disease (COPD) and lower weight. We investigated the amount of physical activity as the time spent in posture and movement and its association with systemic inflammation. [Participants and Methods] In this retrospective cross-sectional pilot study, we evaluated 11 patients with COPD (age, $73 \pm 7$ years; body mass index, $18.9 \pm 2.9 \mathrm{~kg} / \mathrm{m}^{2}$ ). A recently developed triaxial accelerometer was used to measure the time spent in posture and movement. We also evaluated body composition, physiological indexes, and serum levels of inflammatory cytokines. Single correlation coefficients were calculated as the association between physical activity and other outcomes. [Results] The walking time was $36 \pm 32 \mathrm{~min} / \mathrm{d}$, and the standing time was $151 \pm 118$ $\mathrm{min} / \mathrm{d}$. The time spent walking significantly correlated with the fat-free mass index $(r=0.73)$ and interleukin (IL)- 8 level $(r=0.76)$. The time spent standing significantly correlated with the C-reactive protein $(r=0.80)$ and IL-6 levels $(r=0.74)$. [Conclusion] These data indicate that increased physical activity is associated with higher systematic inflammation. We should consider that the systemic inflammation may have been affected by the increased physical activity of the patients with COPD and lower weight in this study.

Key words: Lower weight COPD, Physical activity, Systemic inflammation
\end{abstract}

(This article was submitted Jul. 9, 2020, and was accepted Sep. 9, 2020)

\section{INTRODUCTION}

Chronic obstructive pulmonary disease (COPD) is known to be a systemic inflammatory disease, caused by cigarette smoking, air pollution, and subsequent inflammatory cytokines, such as tumor necrosis factor (TNF)- $\alpha$, interleukin (IL)-6, and IL-8, 2). Systemic inflammation is a recognized risk factor for further co-morbidities commonly observed in patients with COPD, including atherosclerosis ${ }^{3}$, cachexia $^{4}$, anorexia ${ }^{5)}$, and osteoporosis ${ }^{6}$. Muscle wasting in COPD is also affected by systemic inflammation ${ }^{7}$, leading to sarcopenia through malnutrition and physical inactivity ${ }^{8}$. The commonly occurring weight loss and muscle wasting in patients with COPD adversely affects respiratory and peripheral muscle function, exercise capacity, health status, and mortality ${ }^{9-11)}$. In a previous study, systemic inflammation was shown to be aggravated by both

*Corresponding author. Atsuyoshi Kawagoshi (E-mail: acr00009@akita-city-hospital.jp)

(C2020 The Society of Physical Therapy Science. Published by IPEC Inc.

(c) (1) $\odot$ This is an open-access article distributed under the terms of the Creative Commons Attribution Non-Commercial No Deriva-

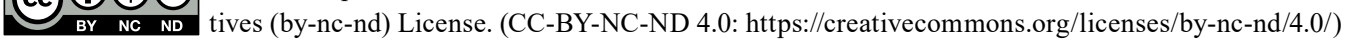


maximal and submaximal exercise in muscle-wasted patients with COPD compared to non-muscle-wasted patients and healthy participants ${ }^{12}$.

Consequently, physical inactivity is a strong predictor for mortality in COPD patients. Daily step count has shown to be significantly related with decreased levels of systemic inflammation measured by plasma C-reactive protein (CRP) and IL-6 levels ${ }^{13}$. However, in this study, participants did not lose weight, and the relationship between body composition and systemic inflammation was not mentioned. The effect of physical activity on systemic inflammation in patients with COPD and lower weight remains unclear, also might be negative on their status according to previous study ${ }^{12}$. Moreover, few studies have reported the time spent in posture and movement as physical activities in patients with COPD ${ }^{14,15)}$, there are however no study to investigate that of physical activities in patients with COPD and lower weight. Therefore, the aim of this study was to investigate the association between systemic inflammation and physical activity status as the time spent in posture and movement in patients with COPD and lower weight.

\section{PARTICIPANTS AND METHODS}

The trial design of this pilot study was a retrospective cross-sectional study. Eleven patients who were diagnosed with mild to very severe COPD ${ }^{16)}$ and entering rehabilitation program at Akita city hospital were enrolled between June 2009 and October 2010 (age; $73 \pm 7$ years, weight; $49.0 \pm 9.6 \mathrm{~kg}$, height; $160.8 \pm 8.2 \mathrm{~cm}$ ). All participants were lower weight defined as \%ideal body weight (\%IBW) $<90 \%$ and decreased body mass index (BMI) $<20.0 \mathrm{~kg} / \mathrm{m}^{2}$ for males and $<18.8 \mathrm{~kg} / \mathrm{m}^{2}$ for females, which has shown to be associated with mortality $\left.{ }^{9}, 11\right)$. The patients were all retired and met the following inclusion criteria: (1) the patient was in a stable condition with no infection or exacerbation of COPD in the prior 3 months; (2) the patient was able to walk unassisted and operate the device to measure physical activity; (3) the patient had no severe and/or unstable cardiac disease, orthopedic disease, or mental disorder that could impair physical activities in daily life.

The assessment of physical activity in daily life, body composition, pulmonary function, submaximal exercise capacity (6MWD; six-minute walk distance), respiratory and quadriceps muscle force, and health-related quality of life were performed by well-trained physical therapists. This study was approved by the medical ethical committee of Akita city hospital and the Akita University School of Health Sciences (approval No. 658). All procedures were performed according to the research ethics guidelines of the Declaration of Helsinki ${ }^{17}$.

The assessment of physical activity in daily life was performed using a tri-axial accelerometer system (Activity Monitoring and Evaluation System [A-MES ${ }^{\text {TM}}$ ], Solid Brains, Kumamoto, Japan) ${ }^{18)}$. The A-MES consists of two sensors $(\mathrm{H} 69 \times$ W $44 \times$ D $11.5 \mathrm{~mm}$ each, weight: $28 \mathrm{~g}$ each), a station, and analytical software used with a personal computer. These sensors are relatively small and light so that they can be attached on the thigh and chest or placed in pockets of clothing (Fig. 1). The physical activity data recorded by the two sensors is sent to the A-MES station and analyzed by A-MES software. The A-MES system measures the time that the wearer has spent in several positions and moving (lying down, sitting, standing, and walking) by using a three-dimensional analysis of acceleration (Fig. 2).

Patients were informed about how to use the A-MES and it was confirmed that each patient understood the device's operation. Each patient was given an A-MES, an instruction book, and the appropriate clothing, and was instructed to measure their physical activity themselves. Since physical activity varies according to the cycle of the seasons ${ }^{19)}$, patients' physical activities were measured disregarding the winter season. The assessment was done for a maximum of 7 consecutive days including weekdays and weekends, and physical activity was measured with the A-MES from waking time until 12 hours after waking time ${ }^{14}, 15$. We used the data of the patients who provided at least two valid days of assessment, which we

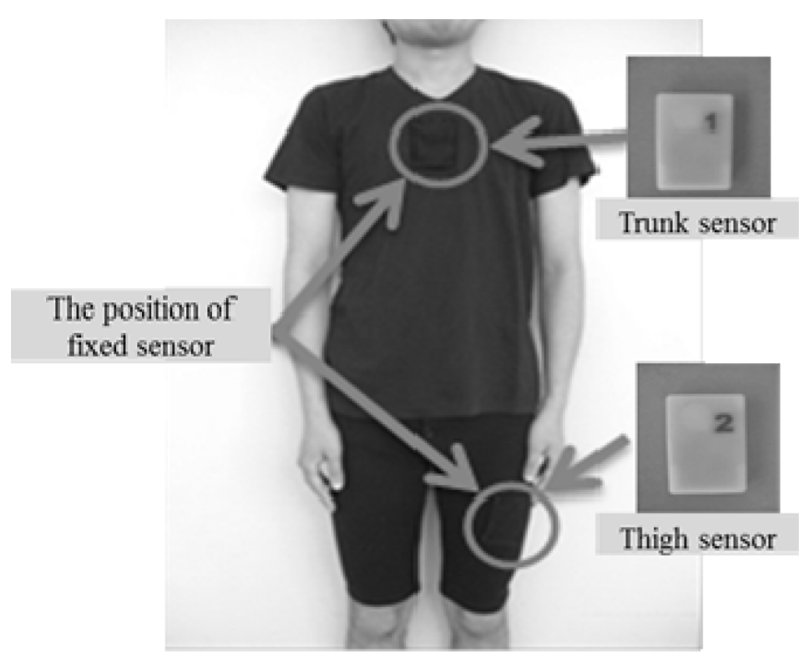

Fig. 1. Activity Monitoring and Evaluation $\operatorname{System}^{\mathrm{TM}}\left(\mathrm{A}-\mathrm{MES}^{\mathrm{TM}}\right)$; Size $69(\mathrm{H}) \times 44(\mathrm{~W}) \times 11.5$ (D) mm. Weight $28 \mathrm{~g}$. 
considered the minimum number of days necessary to assess reliable physical activities in daily life ${ }^{20)}$.

High-sensitivity serum C-reactive protein (CRP) levels were assessed by latex turbidimetric immunoassay (Nittobo Medical; Tokyo, Japan). The analytical sensitivity of this CRP assay is $0.1 \mathrm{mg} / \mathrm{L}$. Serum Tumor necrosis factor (TNF)- $\alpha$, Interleukin (IL)-6, and IL-8 were measured using commercially available enzyme-linked immunosorbent assay kits (SRL, Inc; Tokyo, Japan).

Pulmonary function was assessed as forced vital capacity $(\mathrm{FVC})$, forced expiratory volume in one second $\left(\mathrm{FEV}_{1}\right), \mathrm{FEV}_{1} /$ $\mathrm{FVC}$, and $\% \mathrm{FEV}_{1}$ using a spirometer (HI-701 Multi-Functional Spirometer, Chest M.I., Tokyo, Japan). The mouth pressure was measured as respiratory muscle strength using a respiratory dynamometer (Vitalopower KH-101, Chest M.I.) following American Thoracic Society/European Respiratory Society (ATS/ERS) report recommendations ${ }^{21)}$.

For the weight-bearing index (WBI), the maximum isometric extension and contraction of the quadriceps femoris muscle force were measured at $0^{\circ} / \mathrm{sec} 80^{\circ}$ flexion using the Hydro Musculator GT-160 (OG Giken Co., Tokyo, Japan) ${ }^{22)}$. For the measurements of exercise performance, the patient performed a six-minute walk test (6MWT) according to the ATS guidelines ${ }^{23)}$. The patients were not encouraged during the test. The disease-specific health-related quality of life (QOL) was measured using the Japanese version of the Chronic Respiratory Disease Questionnaire (CRQ) ${ }^{24)}$.

All of assessments have been done before the participants begin our rehabilitation program as baseline assessment. The data of patients were entered and analyzed using IBM SPSS Statistics 21.0 (IBM Corporation, Armonk, NY, USA) Normality in date distribution was assessed using the Shapiro-Wilk test. With p-values $<0.05$ accepted as significant. Pearson's correlation coefficient and Spearman's rank correlation coefficient were used to determine the single correlations between the time spent in different activities (walking, standing, sitting and lying), body composition (i.e., BMI, \%IBW, Fat-Free Mass [FFM], and Fat-Free Mass Index [FFMI]), and, inflammatory markers (IL-6, IL-8, CRP, and TNF- $\alpha$ ).

\section{RESULTS}

The characteristics of 11 patients are presented in Table 1 . The participants consisted of 9 males and 2 females. They had a mean (standard deviation) age of 73 (7) years, BMI $18.9(2.9) \mathrm{kg} / \mathrm{m}^{2}$, and $\mathrm{FEV}_{1} 54.8$ (22.4) \% predicted. Their mean \%IBW was lower than $90 \%$ and also mean FFMI was lower than $15 \mathrm{~kg} / \mathrm{m}^{2}$ defined as underweight. The average time spent in movement and posture during daytime is shown in Table 2. The time spent walking [36 (32) minute/day (min/d)] was the least amount of movement time, then the time spent lying [87 (100) $\mathrm{min} / \mathrm{d}$ ], more in the order of the time spent standing [151 (118) $\mathrm{min} / \mathrm{d}]$, the time spent sitting was the most amount of posture time [446 (111) $\mathrm{min} / \mathrm{d}]$.

The time spent walking was significantly correlated with the FFM $(r=0.641, p=0.046)$, FFMI $(r=0.73$, $p=0.02)$, and interleukin (IL)-8 level ( $\mathrm{r}=0.76, \mathrm{p}=0.02)$. The time spent standing was significantly correlated with the C-reactive protein level $(\mathrm{r}=0.80, \mathrm{p}=0.02)$ and IL-6 level $(\mathrm{r}=0.74, \mathrm{p}=0.04)$. There were no significant correlations between body composition and inflammation markers and the time spent sitting and lying (Table 3 ).

\section{DISCUSSION}

The results of the present study show that the time spent in each posture and movement (walking, standing, sitting, and lying) as physical activity in patients with COPD and lower weight, and increased their walking and standing time were positively associated with inflammatory markers such CRP, IL-6, and IL-8 level. A previous study has shown that an increased daily step count was associated with decreased levels of systemic inflammatory markers in COPD patients without weight loss ${ }^{13)}$. This is the first study showing the association between systemic inflammation and physical activity as the time spent in posture and movement during daytime in patients with COPD and lower weight.

The time spent in posture and movement in patients with COPD has been reported in our previous studies, which represented the walking time was $118 \pm 72 \mathrm{~min} / \mathrm{d}$ and the standing time was $79 \pm 48 \mathrm{~min} / \mathrm{d}$ in the participants who were $21.2 \pm$

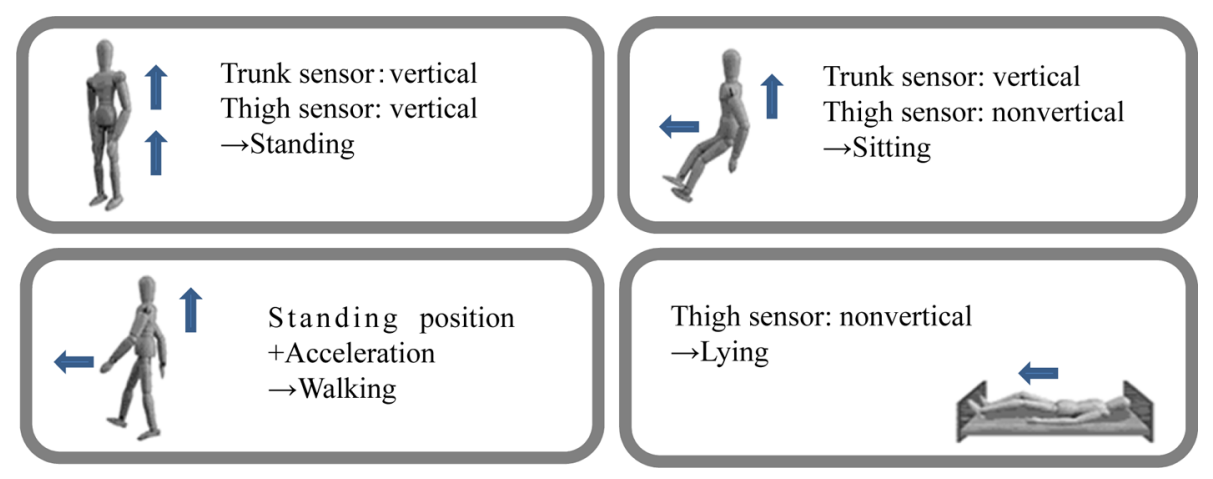

Fig. 2. The measurement of a participants' posture and moving by the A-MES ${ }^{\mathrm{TM}}$ sensors. 
Table 1. Characteristics of the participants

\begin{tabular}{|c|c|}
\hline Gender (M/F) & $9 / 2$ \\
\hline Age (years) & $73 \pm 7$ \\
\hline GOLD (I/II/III/IV) & $2 / 4 / 2 / 3$ \\
\hline BMI $\left(\mathrm{kg} / \mathrm{m}^{2}\right)$ & $18.9 \pm 2.9$ \\
\hline \%IBW (\%) & $86.1 \pm 13.0$ \\
\hline FFM (kg) & $37.3 \pm 6.3$ \\
\hline FFMI $\left(\mathrm{kg} / \mathrm{m}^{2}\right)$ & $14.3 \pm 1.5$ \\
\hline CRP (mg/dL) & $0.9 \pm 0.9$ \\
\hline IL-6 (pg/mL) & $2.0 \pm 1.2$ \\
\hline IL-8 (pg/mL) & $3.4 \pm 2.2$ \\
\hline TNF- $\alpha(\mathrm{pg} / \mathrm{mL})$ & $1.4 \pm 1.0$ \\
\hline $\mathrm{FVC}(\mathrm{L})$ & $2.6 \pm 1.0$ \\
\hline $\mathrm{FEV}_{1}(\mathrm{~L})$ & $1.9 \pm 0.9$ \\
\hline $\mathrm{FEV}_{1} / \mathrm{FVC}(\%)$ & $63.7 \pm 34.8$ \\
\hline $\mathrm{FEV}_{1}(\%$ pred $)$ & $54.8 \pm 22.4$ \\
\hline $\operatorname{PImax}\left(\mathrm{cmH}_{2} \mathrm{O}\right)$ & $74.4 \pm 40.8$ \\
\hline PEmax $\left(\mathrm{cmH}_{2} \mathrm{O}\right)$ & $85.1 \pm 41.5$ \\
\hline 6MWD (m) & $404.6 \pm 169.3$ \\
\hline WBI (kgf/kg) & $0.61 \pm 0.16$ \\
\hline CRQ (total score) & $105.2 \pm 18.4$ \\
\hline \multicolumn{2}{|c|}{$\begin{array}{l}\text { Mean } \pm \text { SD. } \\
\text { GOLD: Global Initiative for Chronic Obstructive Lung } \\
\text { Disease; BMI: body mass index; \%IBW: \% ideal body } \\
\text { weight; FFMI: Fat-free mass index; CRP: C-reactive } \\
\text { protein; IL: Interleukin; TNF: Tumor necrosis factor; } \\
\text { FVC: forced vital capacity; } \text { FEV }_{1} \text { : forced expiratory vol- } \\
\text { ume in one second; PImax: maximum inspiratory mouth } \\
\text { pressure; PEmax: maximum expiratory mouth pressure; } \\
\text { 6MWD: } 6 \text { minutes walking distance; WBI: weight bear- } \\
\text { ing index; CRQ: Chronic Respiratory Disease Question- } \\
\text { naire. }\end{array}$} \\
\hline
\end{tabular}

Table 2. The average of time spent in posture and movement during daytime (from waking time until 12 hours after waking time)

\begin{tabular}{lc}
\hline Walking $(\mathrm{min} / \mathrm{d})$ & $36.3 \pm 32.2$ \\
Standing $(\mathrm{min} / \mathrm{d})$ & $150.7 \pm 117.9$ \\
Sitting $(\mathrm{min} / \mathrm{d})$ & $446.3 \pm 111.3$ \\
Lying $(\mathrm{min} / \mathrm{d})$ & $87.2 \pm 99.9$ \\
\hline Mean \pm SD. &
\end{tabular}

Table 3. The correlation between physical activity and body composition, inflammation markers (Pearson's correlation coefficient)

\begin{tabular}{lcccccccc}
\hline & Walking & p-value & Standing & p-value & Sitting & p-value & Lying & p-value \\
\hline BMI & 0.560 & 0.092 & 0.032 & 0.931 & 0.194 & 0.591 & -0.455 & 0.186 \\
\%IBW & 0.570 & 0.086 & 0.056 & 0.877 & 0.187 & 0.605 & -0.479 & 0.161 \\
FFM & $0.641^{*}$ & 0.046 & -0.229 & 0.525 & 0.021 & 0.955 & 0.026 & 0.944 \\
FFMI $^{\#}$ & $0.758^{*}$ & 0.018 & -0.018 & 0.850 & 0.115 & 0.956 & -0.176 & 0.301 \\
CRP & 0.562 & 0.116 & $0.797^{*}$ & 0.018 & -0.645 & 0.084 & -0.424 & 0.296 \\
IL-6 & -0.065 & 0.868 & $0.742^{*}$ & 0.035 & -0.579 & 0.133 & -0.289 & 0.488 \\
IL-8 & $0.758^{*}$ & 0.018 & 0.120 & 0.777 & -0.066 & 0.877 & -0.306 & 0.461 \\
TNF- $\alpha^{\#}$ & -0.136 & 0.439 & -0.043 & 0.730 & 0.173 & 0.435 & -0.074 & 0.909 \\
\hline
\end{tabular}

"Spearman's rank correlation coefficient, ${ }^{*} \mathrm{p}<0.05$.

BMI: body mass index; \%IBW: \% ideal body weight; FFMI: Fat-free mass index; CRP: C-reactive protein; IL: Interleukin; TNF: Tumor necrosis factor.

$3.5 \mathrm{~kg} / \mathrm{m}^{2}$ of BMI ${ }^{15}$ ). Compared with this, the results of this present study show that the walking time is lower $(36 \pm 32 \mathrm{~min} / \mathrm{d})$ and the standing time is higher $(151 \pm 118 \mathrm{~min} / \mathrm{d})$ respectively (Table 2). Previous studies have reported that physical exercise induced a systemic inflammation response in patients with COPD, which was intensified by exhaustive exercise ${ }^{12,25)}$. Furthermore, van Helvoort et al. ${ }^{12)}$ showed that both maximal and submaximal exercise induced increasing of systemic inflammatory and oxidative responses in muscle-wasted patients with COPD compared with non-muscle-wasted patients and healthy participants. The study suggests that muscle-wasted patients may be frequently exposed to oxidative stress and resultant tissue damage during daily life activities ${ }^{12}$. According to these studies ${ }^{12,25)}$, patients with COPD and lower weight 
have been exposed to more transient inflammatory responses than patients with COPD and not lower weight. It is therefore suggested that this may lead to chronic high inflammatory response in the patients with COPD and lower weight. The participants of this study also have low FFMI, so the results of this present study are supported by the association between systemic inflammation and skeletal muscle mass index in COPD patients with sarcopenia ${ }^{7}$. As a result, the participants in this study might has decreased their walking time and increased standing time instead.

In elderly patients with COPD, physical inactivity is a key factor in the development of sarcopenia and a predictor of mortality and disability ${ }^{7}$. The participants of this study exhibited lower weight and lowered FFMI $\left(<15 \mathrm{~kg} / \mathrm{m}^{2}\right)$, associated with increased mortality in COPD ${ }^{26)}$. These are supported by our results from studying the correlation between FFM, FFMI, and the time spent walking. Anti-inflammatory effect has been observed through myokine production by muscle cells through contraction due to physical exercise ${ }^{27}$. The enhancement of inflammatory responses by exercise or physical activity might be a compensatory mechanism leading to reduction of muscle mass. Therefore, it must be noted that unreasonable increases in physical activity in patients with COPD patients with reduced muscle mass or lower weight might be rather deteriorating to the systemic inflammation. The time spent sitting have moderate negative correlation coefficients with CRP even not significantly (Table 3). This might be dependent on other parameters (walking, standing, and lying), because the time spent standing have significantly positive correlation coefficients with CRP. Moreover, it might suggest that to spend more time in sitting position is preventable to not increase systematic inflammation in the patients with COPD and lower weight.

Based on the above, a combination of nutritional therapies that have an anti-inflammatory effect and exercise therapy with low intensity is a countermeasure ${ }^{28,29)}$. In a previous systematic review, it has been reported that nutritional supplementation has positive effects on body weight, fat mass, and FFM when it is provided alone to patients with COPD (especially if malnourished) and when used as an adjunct to exercise training ${ }^{28)}$. Sugawara et al. ${ }^{29)}$ showed that additional anti-inflammatory nutritional supplementation therapy with whey peptide for stable elderly patients with $\mathrm{COPD}\left(\% \mathrm{IBW}<110 \%, \% \mathrm{FEV}_{1}<80 \%\right)$ under low-intensity exercise therapy improved body weight, exercise tolerance, and health-related quality of life by inhibiting systemic inflammation as an additive effect. Moreover, it might be important to consider the improvement in exercise tolerance for increased physical activity as it has been shown that an increase in activity is expected in a state that ensures exercise tolerance ${ }^{30)}$.

An important limitation of the present study is the single correlation between physical activity and systemic inflammation presented due to small sample size and the single-centered study; therefore, important factors were not taken into consideration, e.g., age, gender, comorbidities, smoking status, severity of COPD, and exercise intolerance, which could have an influence on the relation between physical activity and systemic inflammation. Furthermore, this study cannot consider comparison with the control group, such as the patients with COPD and not lower weight. Therefore, the characteristics of the participants in this study are only inferred from comparisons with the results of previous study. Further studies with a larger sample size and control group are suggested so that multivariate analyses considering other confounding-factors of systemic inflammation can be conducted.

In summary, our present findings confirmed the amount of physical activities as time spent in movement and posture in patients with COPD and lower weight and the association with their systemic inflammation. These data suggest that increased physical activity in COPD patients and lower weight might be associated with higher systematic inflammation. Further studies are needed to examine the influence of physical activities on systemic inflammation with a larger sample size whose wide variety of COPD severity and multivariate analyses in order to consider other cofactors of systemic inflammation.

\section{Conflict of interest}

The authors have no conflicts of interest to declare.

\section{REFERENCES}

1) Schols AM, Buurman WA, Staal van den Brekel AJ, et al.: Evidence for a relation between metabolic derangements and increased levels of inflammatory mediators in a subgroup of patients with chronic obstructive pulmonary disease. Thorax, 1996, 51: 819-824. [Medline] [CrossRef]

2) Broekhuizen R, Wouters EF, Creutzberg EC, et al.: Raised CRP levels mark metabolic and functional impairment in advanced COPD. Thorax, 2006, 61: 17-22. [Medline] [CrossRef]

3) Ross R: Atherosclerosis — an inflammatory disease. N Engl J Med, 1999, 340: 115-126. [Medline] [CrossRef]

4) Kotler DP: Cachexia. Ann Intern Med, 2000, 133: 622-634. [Medline] [CrossRef]

5) Johnson PM, Vogt SK, Burney MW, et al.: COX-2 inhibition attenuates anorexia during systemic inflammation without impairing cytokine production. Am J Physiol Endocrinol Metab, 2002, 282: E650-E656. [Medline] [CrossRef]

6) Raisz LG: Physiology and pathophysiology of bone remodeling. Clin Chem, 1999, 45: 1353-1358. [Medline]

7) Byun MK, Cho EN, Chang J, et al.: Sarcopenia correlates with systemic inflammation in COPD. Int J Chron Obstruct Pulmon Dis, 2017, 12: 669-675. [Medline] [CrossRef]

8) Jones SE, Maddocks M, Kon SS, et al.: Sarcopenia in COPD: prevalence, clinical correlates and response to pulmonary rehabilitation. Thorax, 2015, 70: 213-218. [Medline] [CrossRef]

9) Wilson DO, Rogers RM, Wright EC, et al. The National Institutes of Health Intermittent Positive-Pressure Breathing Trial: Body weight in chronic obstructive pulmonary disease. Am Rev Respir Dis, 1989, 139: 1435-1438. [Medline] [CrossRef] 
10) Nishimura Y, Tsutsumi M, Nakata H, et al.: Relationship between respiratory muscle strength and lean body mass in men with COPD. Chest, 1995, 107: 1232-1236. [Medline] [CrossRef]

11) Gray-Donald K, Gibbons L, Shapiro SH, et al.: Nutritional status and mortality in chronic obstructive pulmonary disease. Am J Respir Crit Care Med, 1996, 153: 961-966. [Medline] [CrossRef]

12) Van Helvoort HA, Heijdra YF, Thijs HM, et al.: Exercise-induced systemic effects in muscle-wasted patients with COPD. Med Sci Sports Exerc, 2006, 38: 1543-1552. [Medline] [CrossRef]

13) Moy ML, Teylan M, Weston NA, et al.: Daily step count is associated with plasma C-reactive protein and IL-6 in a US cohort with COPD. Chest, 2014, 145 542-550. [Medline] [CrossRef]

14) Pitta F, Troosters T, Spruit MA, et al.: Characteristics of physical activities in daily life in chronic obstructive pulmonary disease. Am J Respir Crit Care Med, 2005, 171: 972-977. [Medline] [CrossRef]

15) Kawagoshi A, Kiyokawa N, Sugawara K, et al.: Quantitative assessment of walking time and postural change in patients with COPD using a new triaxial accelerometer system. Int J Chron Obstruct Pulmon Dis, 2013, 8: 397-404. [Medline] [CrossRef]

16) Global Initiative for Chronic Obstructive Lung Disease. Global strategy for the diagnosis, management and prevention of chronic obstructive pulmonary disease- executive summary. NHLB/WHO workshop report. Bethesda: National Heart, Lung, and Blood Institute; April 2001. Update of the Management Sections, Date update: February 2013. www.goldcopd.com (Accessed Oct. 23, 2013)

17) World Medical Association Declaration of Helsinki ethical principles for medical research involving human subjects. Adapted by 59th WMA General Assembly, Seoul, 2008 Oct. http://www.wma.net/en/30publications/10policies/b3/ 17c.pdf (Accessed Aug. 28, 2013)

18) Sakata S, Nagata M, Nojiri S: Approach to the measurement of ADL (Activities of Daily Living). Den-O-Ken Technical Report. 2002, 12: 19-25 (in Japanese)

19) Sewell L, Singh SJ, Williams JE, et al.: Seasonal variations affect physical activity and pulmonary rehabilitation outcomes. J Cardiopulm Rehabil Prev, 2010, 30: 329-333. [Medline] [CrossRef]

20) Benzo R: Activity monitoring in chronic obstructive pulmonary disease. J Cardiopulm Rehabil Prev, 2009, 29: 341-347. [Medline] [CrossRef]

21) American Thoracic Society/European Respiratory Society: ATS/ERS Statement on respiratory muscle testing. Am J Respir Crit Care Med, 2002, 166: 518624. [Medline] [CrossRef]

22) Decramer M, Lacquet LM, Fagard R, et al.: Corticosteroids contribute to muscle weakness in chronic airflow obstruction. Am J Respir Crit Care Med, 1994, 150: 11-16. [Medline] [CrossRef]

23) ATS Committee on Proficiency Standards for Clinical Pulmonary Function Laboratories: ATS statements: guidelines for six-minute walk test. Am J Respir Crit Care Med, 2002, 166: 111-117. [CrossRef]

24) Guyatt GH, Berman LB, Townsend M, et al.: A measure of quality of life for clinical trials in chronic lung disease. Thorax, 1987, 42: 773-778. [Medline] [CrossRef]

25) van Helvoort HA, van de Pol MH, Heijdra YF, et al.: Systemic inflammatory response to exhaustive exercise in patients with chronic obstructive pulmonary disease. Respir Med, 2005, 99: 1555-1567. [Medline] [CrossRef]

26) Schols AM, Broekhuizen R, Weling-Scheepers CA, et al.: Body composition and mortality in chronic obstructive pulmonary disease. Am J Clin Nutr, 2005, 82: 53-59. [Medline] [CrossRef]

27) Pedersen BK: The diseasome of physical inactivity — and the role of myokines in muscle — fat cross talk. J Physiol, 2009, 587: 5559-5568. [Medline] [CrossRef]

28) Ferreira IM, Brooks D, White J, et al.: Nutritional supplementation for stable chronic obstructive pulmonary disease. Cochrane Database Syst Rev, 2012, 12: CD000998 10.1002/14651858.CD000998.pub3. [Medline]

29) Sugawara K, Takahashi H, Kashiwagura T, et al.: Effect of anti-inflammatory supplementation with whey peptide and exercise therapy in patients with COPD Respir Med, 2012, 106: 1526-1534. [Medline] [CrossRef]

30) Blondeel A, Demeyer H, Janssens W, et al.: The role of physical activity in the context of pulmonary rehabilitation. COPD, 2018, 15: 632-639. [Medline] [CrossRef] 